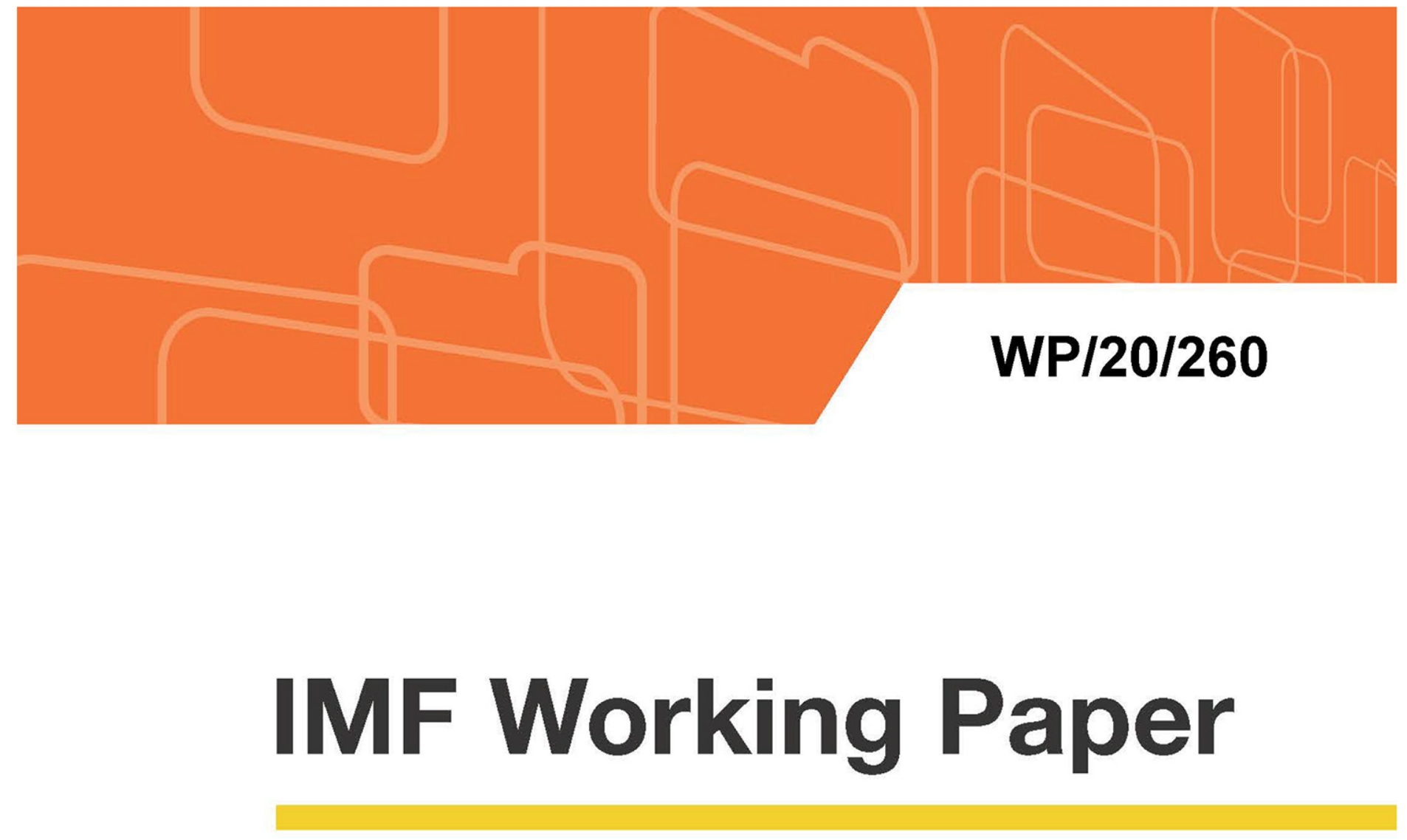

\title{
Corporate Vulnerabilities in Vietnam and Implications of COVID-19
}

by Thilo Kroeger, Anh Thi Ngoc Nguyen, Yuanyan Sophia Zhang, Pham Dinh Thuy, Nguyen Huy Minh, and Duong Danh Tuan

IMF Working Papers describe research in progress by the author(s) and are published to elicit comments and to encourage debate. The views expressed in IMF Working Papers are those of the author(s) and do not necessarily represent the views of the IMF, its Executive Board, or IMF management.

$$
\text { I N T ER N A T I O N A L M O NETAR Y FU N D }
$$




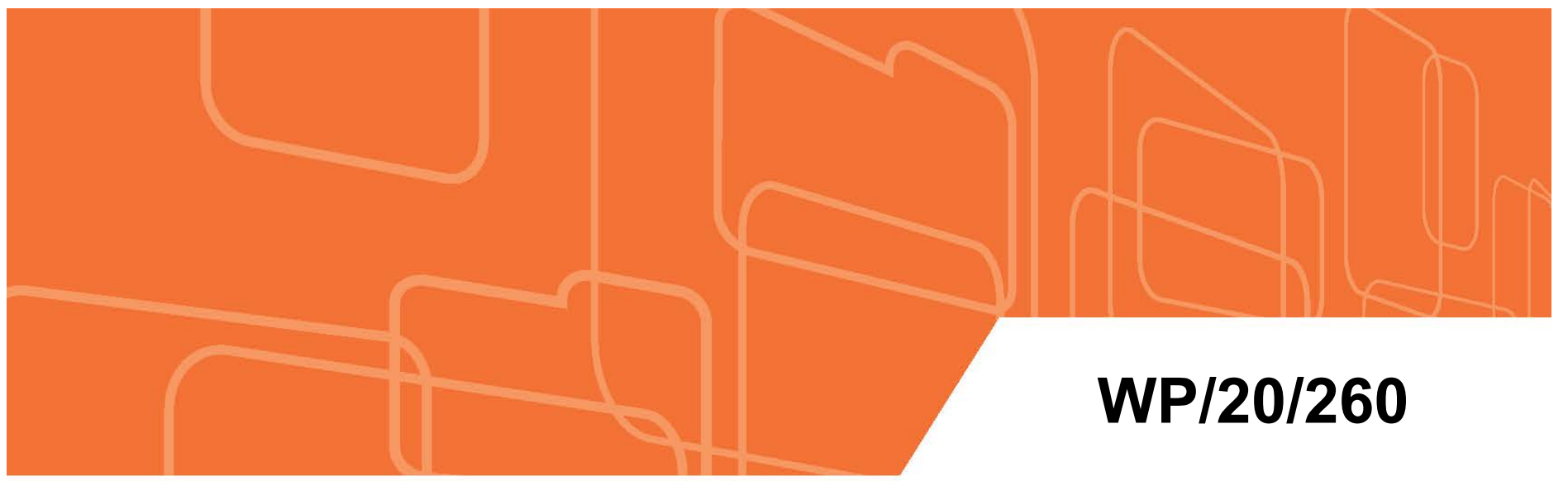

\section{IMF Working Paper}

\section{Corporate Vulnerabilities in Vietnam and Implications of COVID-19}

by Thilo Kroeger, Anh Thi Ngoc Nguyen, Yuanyan Sophia Zhang, Pham Dinh Thuy, Nguyen Huy Minh, and Duong Danh Tuan

IMF Working Papers describe research in progress by the author(s) and are published to elicit comments and to encourage debate. The views expressed in IMF Working Papers are those of the author(s) and do not necessarily represent the views of the IMF, its Executive Board, or IMF management. 


\title{
IMF Working Paper
}

\section{Asian Pacific Department}

Corporate Vulnerabilities in Vietnam and Implications of COVID-19

Prepared by Thilo Kroeger, Anh Thi Ngoc Nguyen, Yuanyan Sophia Zhang ${ }^{1}$,

Nguyen Huy Minh, Pham Dinh Thuy, and Duong Danh Tuan

Authorized for distribution by Era Dabla-Norris

November 2020

IMF Working Papers describe research in progress by the author(s) and are published to elicit comments and to encourage debate. The views expressed in IMF Working Papers are those of the author(s) and do not necessarily represent the views of the IMF, its Executive Board, or IMF management.

\begin{abstract}
The paper uses firm-level data to assess the financial health of the Vietnamese non-financial corporate sector on the eve of pandemic. Our analysis finds that smaller domestic firms were particularly vulnerable even by regional comparison. A sensitivity analysis suggests that the COVID-19 shock will have a substantial impact on firms' profitability, liquidity and even solvency, particularly in the hardest hit sectors that are dominated by SMEs and account for a sizeable employment share, but large firms are not immune to the crisis. Risks of default can propagate more broadly through upstream and downstream linkages to industries not directly impacted, with stresses potentially translating into an increase in corporate bankruptcies and bank fragility. Policy measures taken in the immediate aftermath of the crisis have helped alleviate liquidity pressures, but the nature of policy support may have to pivot to support the recovery.
\end{abstract}

JEL Classification Numbers: G30; G32; G33; G38; H12; O16

Keywords: Corporate Vulnerability, Debt at risk, COVID-19, ASEAN, Leverage, Profitability

Author's E-Mail Address: TKroeger@imf.org, ANguyen4@,imf.org, YZhang@,imf.org, nhminh@gso.gov.vn, pdthuy@gso.gov.vn, ddtuan@gso.gov.vn

\footnotetext{
${ }^{1}$ The authors are grateful to Era Dabla-Norris and Francois Painchaud for helpful comments, the General Statistics Office of Vietnam for data sharing, Anh Thi Van Nguyen for coordination, Tran Thi Bich for technical assistance and participants at the IMF-GSO webinar for discussion. All remaining errors are our own.
} 
Table of Contents

I. Introduction

II. Literature Review $\underline{4}$

III. Data and Analytical Approach $\underline{5}$

IV. Vietnam: Corporate Balance Sheet Conditions Prior to COVID-19

V. Impact of COVID-19: Risk of Default, Labor Market Implications, and Risk Propagation 12

VI. Conclusions and Policy Implications

FIGURES

1. Gross Profitability, by Industries, Ownership Types and Sizes $\underline{7}$

2. Operating Profitability, by Industries, Ownership Types and Sizes $-\underline{8}$

3. Net Operating Cash flow/Current Liability Ratio $\underline{9}$

4. Leverage and Investment Financing Sources $\underline{10}$

5. Interest Coverage Ratio and Debt-at-Risk $-\frac{11}{15}$

6. Upstream and Downstream Linkages Across Industries $\underline{15}$

TABLE

1. Sensitivity Analysis for Affected Firms $\underline{14}$

Annex 1. Summary Statistics of Key Variables Across Asian Countries $-19$

Annex 2. Overview of Vietnamese Enterprise Survey: Distribution by Firm Characteristics $-\frac{20}{21}$ Annex 3. Summary Statistics of Vietnamese Enterprise Survey 21 Annex 4. Regional Comparison of Liquidity Coverage $\underline{22}$

Annex 5. Recent Firm-level Survey on the Impact of COVID-19 $\underline{23}$ Annex 6. Key Policy Measures to Support Businesses in Response to COVID-19 24

References 25 


\section{INTRODUCTION}

The COVID-19 shock is expected to sharply lower growth in Vietnam and weigh on corporate balance sheets. Contact-intensive sectors (e.g., hospitality, entertainment, retail), and low valueadded manufacturing, in particular, have seen a significant contraction in domestic and external demand. As a result, corporates in these sectors are experiencing liquidity shortages, and could potentially face deeper liquidity strains and solvency stress if the recovery is protracted. From a macro-perspective, corporate sector vulnerabilities in Vietnam were elevated even prior to this crisis. Non-financial corporate (NFC) sector's debt was rising, leaving the sector vulnerable to a sharp fall in revenues. Also, non-performing loans (NPLs) in the banking system-while declining-remained high. These two features suggest that a prolonged period of low growth runs the risk of fueling larger-scale corporate and financial distress.

Against this background, understanding the scale and nature of risks and where these are concentrated is important for policy formulation. The authorities swiftly implemented a macroeconomic and financial package to support firm liquidity in the early stages of the crisis. ${ }^{2}$ Fiscal policy provided "on-budget" support measures, such as deferral of tax obligations and other quasifiscal measures such as cuts in electricity prices. Monetary policy relied on both traditional policy rate cuts and other targeted easing measures. Financial sector policies supported firms through time bound moratoriums on loan repayments and interest rate deferrals, among others.

As the crisis progresses, there is a need to reassess policy options, which will require an understanding of the nature of risks (liquidity vs. solvency), where risks are mostly concentrated (by size, industry and ownership types), and the labor market implications. This paper aims to assess vulnerabilities of the Vietnamese corporate sector prior to the crisis and its financial resilience to the COVID-19 shock using detailed firm-level data from ORBIS and the confidential Vietnamese enterprise survey from the General Statistics Office of Vietnam. In particular, the paper aims to:

- Assess corporate sector vulnerabilities prior to the COVID-19 shock and how Vietnam compares to other countries in the region and examine which sectors and firm were the most vulnerable.

- Identify the characteristics of firms that are a heightened risk of default in response to the COVID-19 pandemic and implications for the labor market; and analyze the sensitivity to adverse spillovers from upstream and downstream sectors;

- Examine the extent to which fiscal and financial sectors measures implemented to support firms have ameliorated liquidity and balance sheet risks using a quantitative simulation.

We find that Vietnam's corporate sector, which is dominated by small and medium enterprises, entered the crisis with relatively weak balance sheet positions. Small and medium enterprises (SMEs), particularly domestic private firms in contact-intensive sectors, were much less profitable than

\footnotetext{
${ }^{2}$ The intensity of containment measures peaked in March and April in Vietnam, and restrictions on movement and business operations were gradually relaxed from May onward as infections fell.
} 
regional peers, suggesting cash flow problems and weak debt servicing capacity. SMEs also accounted for a sizable share of employment of informal workers, which are at higher risk of job losses or wage cuts on account of the pandemic. Larger firms, despite exhibiting higher profitability, were much more leveraged by regional standards. The immediate policy response has alleviated potential liquidity shortages and helped firms survive the initial shock and prevent a more severe economic collapse. However, as the crisis progresses, the nature of support will need to be reconfigured to address specific pockets of vulnerabilities and potentially rising insolvency risks. A robust and sustained recovery will also hinge on improving firm productivity by facilitating resource reallocation.

The paper is organized as follows. The next section II provides a brief review of the recent literature. Section III describes the data and methodology. Section IV assesses corporate sector vulnerabilities prior to the COVID-19 shock and provides a cross-country comparison. Section V examines the implications of COVID-19 and assesses the impact of policy measures undertaken to support firms. Section VI concludes.

\section{LITERATURE REVIEW}

Recent country-level surveys show that the pandemic is having a profound impact on business activities, especially for small and medium sized enterprises (SMEs). Around 80 percent of SMEs in the UK and more than 50 percent of SMEs in the US reported revenue losses on account of the COVID-19 pandemic. ${ }^{3}$ A recent Vietnamese enterprise survey reports that close to 90 percent of the firms surveyed were affected by COVID-19 to some extent. Almost 60 percent of firms surveyed reported facing weaker demand and half of the firms experienced supply chain disruptions (Vietnamese Corporate Survey, 2020).

A company is considered illiquid if its liquid assets (cash and financial investments) are insufficient to cover operational net cash outflows and debt repayments. Demmou et al. (2020) find that 35-38 percent of European firms would face liquidity shortfalls after three months on account of social distancing measures. If full containment lasted seven months, more than 50 percent of firms would face a liquidity shortfall. Didier et al. (2020) find that as business revenue plummeted in the US, corporate cash flows have collapsed at an unprecedented scale, and in some of the hardest-hit industries (e.g. restaurants, retail), available cash stock would only cover less than 30 days of operating expenses.

Liquidity shortages can also turn into a solvency crisis if the book value of debt for a company exceeds the value of assets (i.e. if it has negative equity). With revenue streams impacted for an extended period and fewer options to deal with liquidity shortfalls, the longer-term viability of firms could be impaired, and firm closures and bankruptcies follow. A sensitivity analysis using data on listed firms for the ASEAN and Vietnam (Kim et al., 2020) suggests that over half of the total

\footnotetext{
${ }^{3}$ Albonico et al. (2020) and U.S. Census Bureau Small Business Pulse Survey.
} 
corporate debt in these countries could be at risk of distress on account of the pandemic. Modelbased simulations (Gourinchas et al, 2020) using firm level data for 17 countries predict an almost three-fold increase in aggregate SME bankruptcy rates by the end of 2020 due to the impact of COVID-19 in the absence of liquidity support and public intervention. A corporate solvency crisis, in turn, could have significant longer-term adverse impact on the macroeconomy, dragging down employment, productivity, growth and well-being (Boot et al., 2020).

A firm's ability to continue operating under liquidity constraints depends on whether it can raise additional financing and/or adjust operating expenses. However, even viable firms facing liquidity constraints may not have sufficient collateral to bridge a liquidity shortfall with additional debt. Further, highly leveraged firms may be unable to bridge the crisis through further bank loans. Adjusting operating expenses could entail laying off workers or lowering wages, especially in contact-intensive services sectors, with significant labor market repercussions.

Government support is important to help illiquid but viable firms manage the crisis. Public authorities around the world have taken unprecedented measures to contain the health and economic implications of the virus (IMF Fiscal Monitor 2020), ranging from tax deferrals, financial support of debt repayment to temporary support to wage payments. Demmou et al. (2020) provide a quantitative simulation exercise suggests that a decisive public intervention, especially support for wage payments is a critical policy for curbing the liquidity crisis and preventing permanent scarring of the economy.

\section{Data And Analytical Approach}

This paper uses two data sources to examine corporate vulnerabilities in Vietnam. First, we use based on firms' balance sheet and income statements from the Bureau van Dijk's Orbis Database to compare Vietnam's corporate vulnerabilities with its Asian peers. ${ }^{4}$ The Orbis Database is well suited for this purpose for three reasons. First, it provides detailed information on balance sheet conditions across many Asian countries. Second, the sample coverage is reasonably representative covering both large and small enterprises, particularly for Vietnam (over 488,446 observations with similar distribution of firm characteristics as the enterprise survey, and comparator countries). In comparison, other datasets are limited to listed firms, and ignore the dominant share of SMEs in the Vietnamese economy. Third, Orbis data is relatively updated. Annex 1 provides summary statistics of the relevant variables from the Orbis data.

The other data sources used in the paper is the confidential Vietnamese Enterprise Survey, which allows us to assess corporate vulnerabilities at a more granular level (firm type, ownership, and detailed sectors). The survey covers 517,806 registered firms, and the sample is representative across industries, sizes, ownership types, and locations. The survey is conducted on an annual basis and covers information ranging from balance sheet conditions, financing sources, production, to firm

\footnotetext{
4 The Asian sample includes Indonesia, Malaysia, Philippines, Singapore, and Thailand, as well as China and the Republic of Korea.
} 
characteristics such as sizes, ownership types, locations, and industries. Survey questions differ somewhat from year to year. For example, the 2017 survey has the most detailed information on balance sheet conditions, such as interest payments, an important variable needed to calculate interest coverage ratio, which is not available in other years. Hence, we use the 2017 survey to assess the baseline corporate vulnerability prior to the crisis (See Annex 2 and Annex 3 for an overview and a summary statistics of the Vietnamese Enterprise Survey).

We assess corporate balance sheet conditions based on four key aspects-profitability, financing structure, liquidity and solvency conditions.

- Profitability: Gross profitability, measured as revenue less cost of goods sold, captures firm value added, and the ability to sell its products at a higher margin over input costs. This measure tends to differ across industries given the nature of products. Operating profitability, measured as gross profit less operational costs, or EBIT (earnings before interest and tax), indicates the firms' ability to generate sufficient revenues to cover production and financing costs. If EBIT is low for a long period, bankruptcy risks would be higher.

- $\quad$ Financing structure: Corporate's leverage ratio, defined as total liability to total equity, reflects firms' reliance on external borrowing and the potential debt servicing obligation. The sources of financing also matter. For instance, a higher reliance on bank financing imply banks' exposure to corporate vulnerabilities.

- $\quad$ Liquidity: We evaluate firm's liquidity using three measures. The first measure is cash at hand, which calculates the number of days that available cash and cash equivalents can cover operating expenses. The second, cash flow liquidity ratio (net operating cash flow/current liability) measures the coverage of cash flow on short-term liability. The third measure is the current ratio (current asset/current liability) which measures if cash and other non-cash liquid assets are sufficient to cover short-term liabilities.

- Solvency: The interest coverage ratio (ICR), defined as EBIT divided by interest payments is the most direct indicator of firms' debt servicing capacity. If the ICR falls below 1 , the respective firm is unable to cover immediate costs of debt and will have to refinance through higher debt levels increase leverage and lowering the value of equity, or default on the debt. 
IV. Vietnam: Corporate Balance Sheet Conditions Prior to COVID-19

Vietnamese firms were much less profitable than the peers (Figure 1, 2). Using the ORBIS dataset, we find that gross profitability was significantly lower in Vietnam than in the ASEAN-5, China and Korea. This holds true across ownership types and firm size, which can be due to variety of factors, including lower production value-added, and limited access to cheap inputs. Operating profitability was also very low in Vietnam by regional standards, particularly among SMEs. Data from both Orbis and the Vietnamese Enterprise

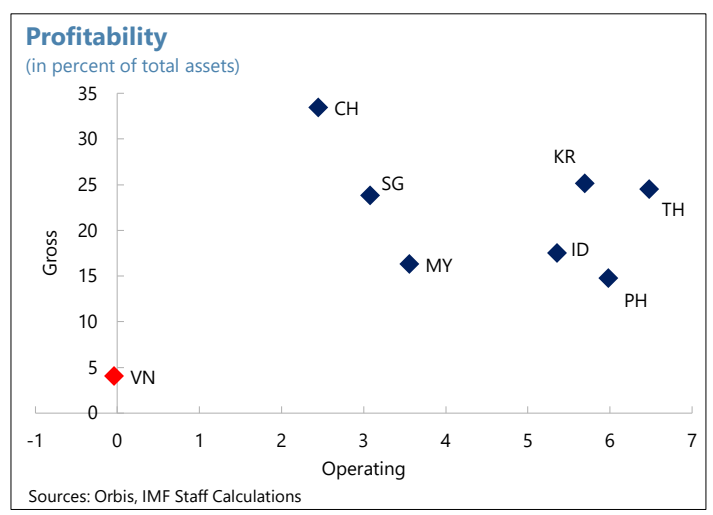
Survey suggest that even prior to the crisis, about half of the enterprises were making losses, and most of these were SMEs. Weak operating profitability among SMEs reflects high operating expenses owing to low economy of scale, cumbersome post-registration procedures, land limited access to cheaper resources such as infrastructure, land, and credit (OECD, 2019).

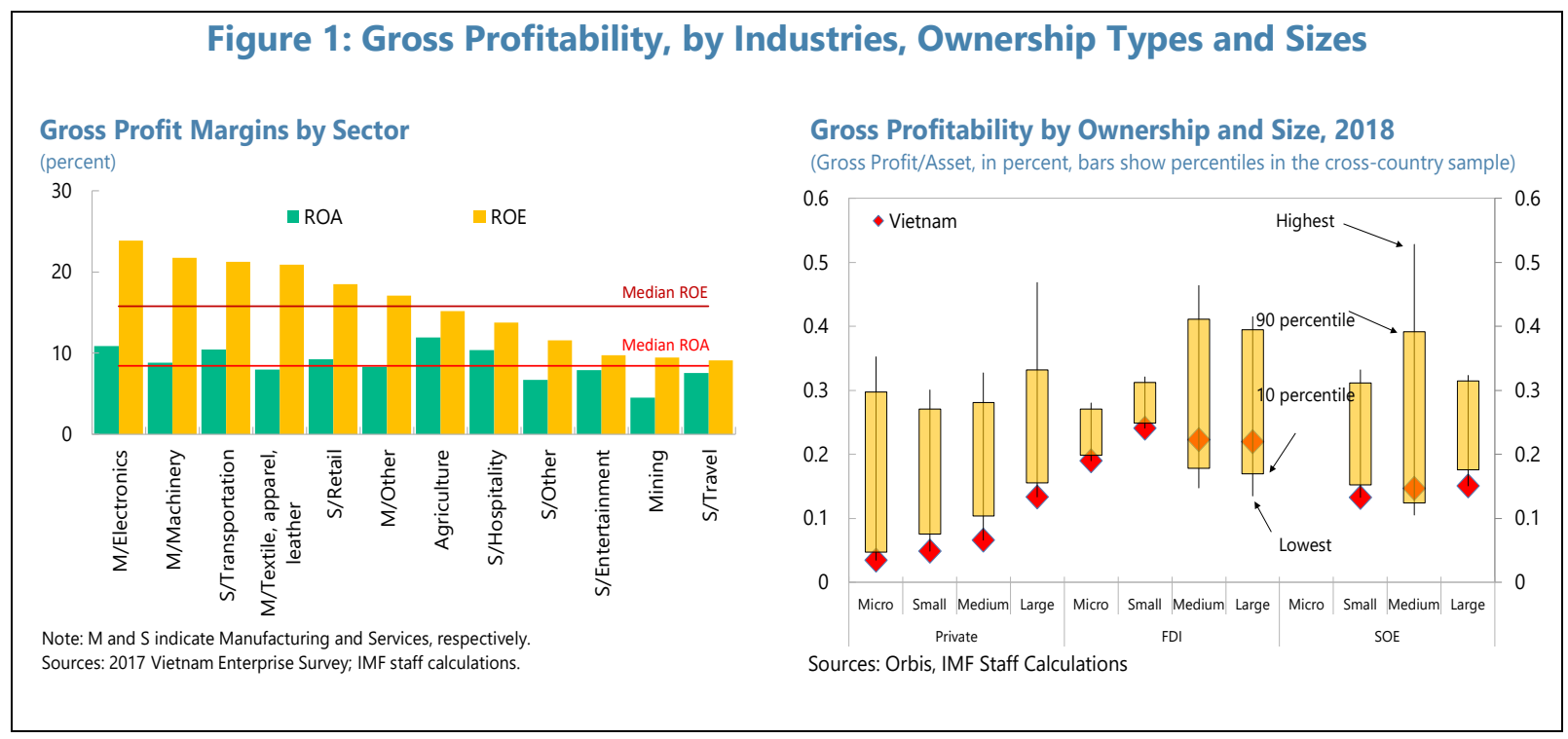




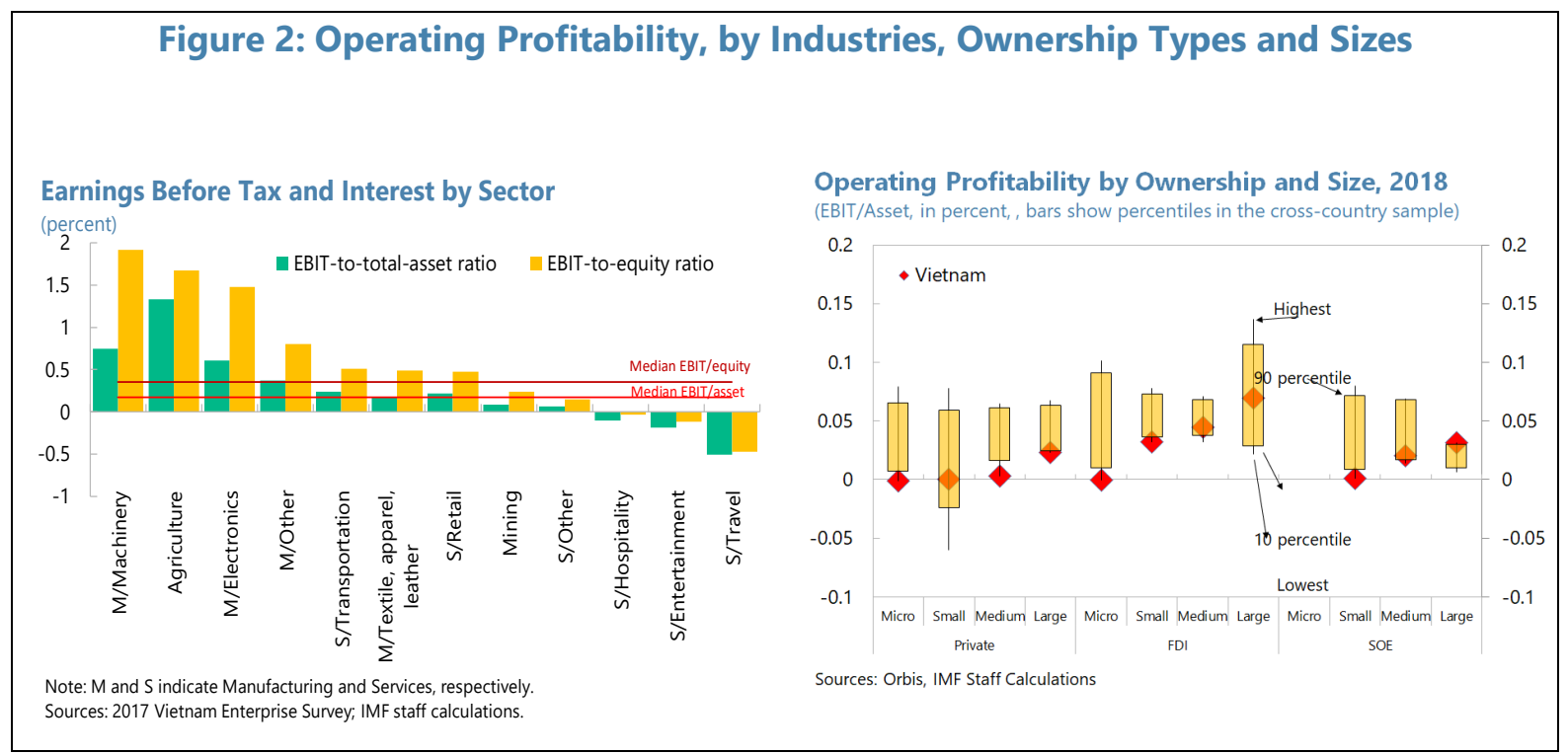

Zooming in on sectors, we find that profitability diverged across sectors, and was particularly weak among smaller domestic private enterprises, which dominate the service sectors. As in other countries in the region, SMEs and micro firms (less than 10 employees) were the least profitable, although they accounted for the bulk of value added and employment. ${ }^{5}$ Further, SMEs tended to dominate the services sectors that are most vulnerable to the COVID-19 shock. Compared to other Asian countries, profitability of SMEs and private enterprises is among the lowest in the region. In contrast, larger Vietnamese FDI firms were much more profitable and comparable to Asian peers, possibly due to favorable policy treatments and better access to resources than private SMEs. ${ }^{6}$ In particular, SOEs in Vietnam were more profitable than private domestic enterprises controlling for size. This runs in contrast to the findings in other countries, for example, in Malaysia and China, where private enterprises were more profitable than SOEs.

From an industry perspective, high-tech industries, such as electronics and electrical equipment enjoyed higher gross and operating profitability due to higher value-added, and preferential policy treatments for FDI firms that lowered operating expenses. Service sector firms, on the other hand, were dominated by SMEs and privately-owned firms, hence less profitable. In the past five years, the profitability divergence been FDI and private domestic firms in Vietnam has widened, with larger FDI firms becoming more profitable while profitability of domestic private firms has declined.

\footnotetext{
${ }^{5}$ This result of lower profitability in SMEs is consistent with evidence from other countries in Asia (APD REO 2019, Toshino and Taghizadeh-Hesary 2018, Colacelli and Hong 2019)

${ }^{6} \mathrm{FDI}$ enterprises in Vietnam are highly integrated in global value chains and also tend to benefit from easier access to technology and know-how.
} 
Corporates' cash liquidity was weak in some of sectors hit hardest by the pandemic. ${ }^{7}$ On average, available cash stock could only cover around 2 months of operating expenses, one of the lowest among the Asian peers. In some of the hardest-hit sectors such as, restaurants, travel, textiles industries, the median cash coverage is less than 2 months. There appears to be no clear differences in cash-on-hand by ownership type, but smaller firms accumulated a higher cash stock. However, if the crisis persists, the available cash stock could easily run out without new sales. An alternative

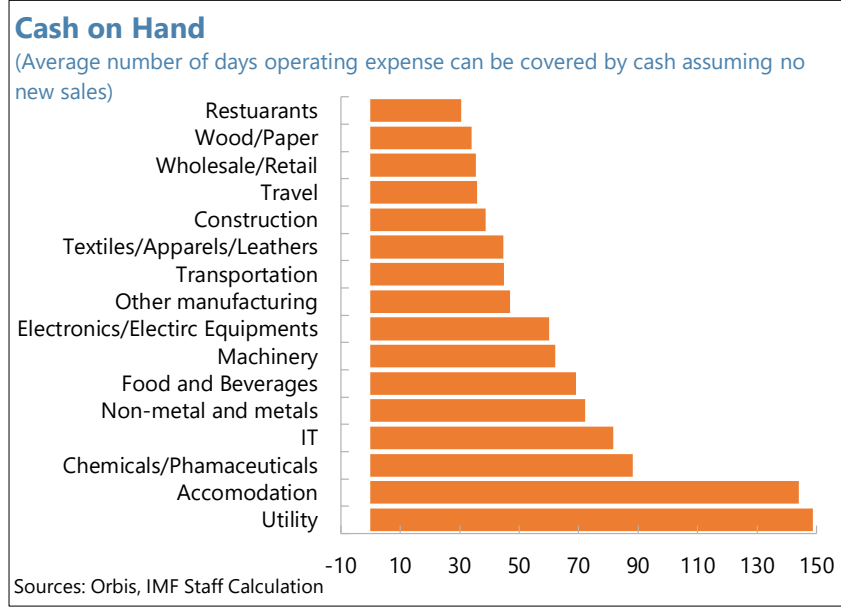
liquidity measure based on cash flows (rather than stock, Figure 3), defined as operating cash flow/current liability, also confirms weak liquidity in the hardest-hit sectors. Further it shows that smaller and private firms had weaker ability to generate sufficiently cash flow to cover short-term liabilities, in line with their weak profitability. The current ratio, calculated as current asset/current liability, was close to 2 (median) indicating broadly adequate liquidity if the firm used non-cash liquid asset to cover its current liability (Annex 4).

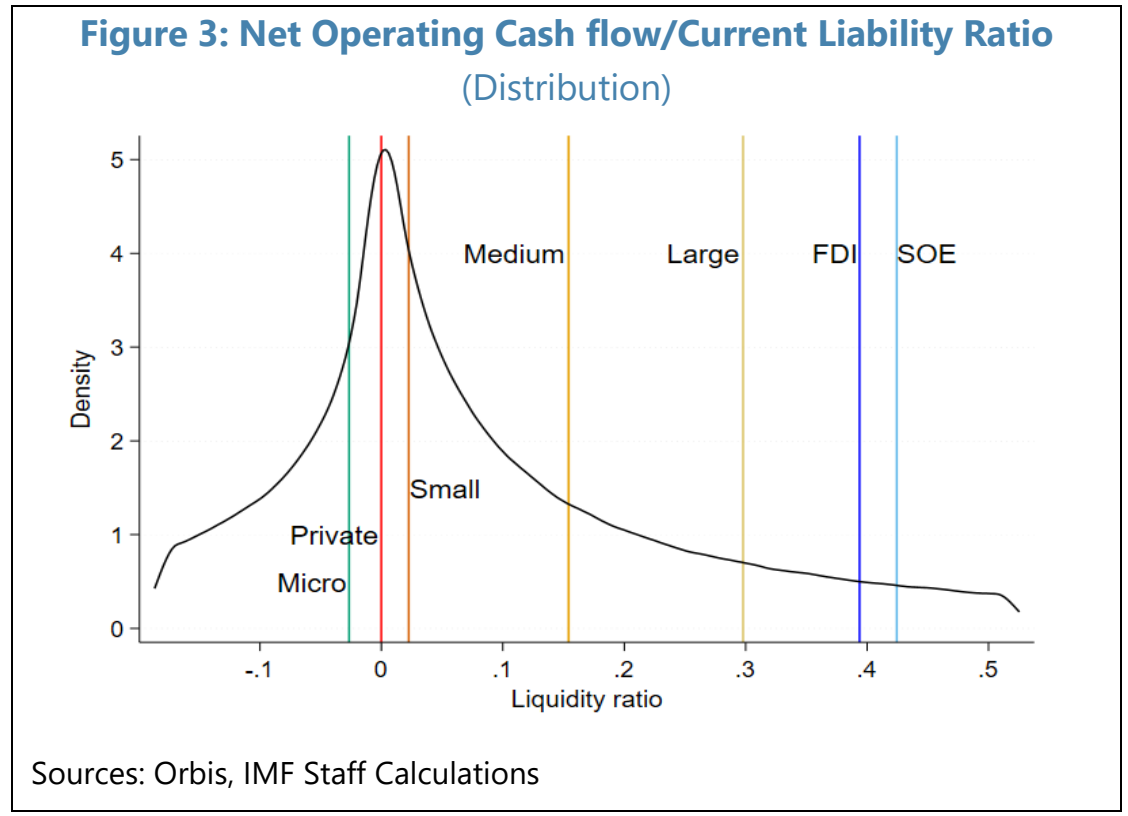

SMEs in Vietnam were largely reliant on retained earnings, but large firms were highly leveraged, even by regional standards. Median leverage, measured as the debt-to-equity ratio, was about 0.3

\footnotetext{
7 This analysis is based on Orbis as the Vietnamese enterprise survey does not have information on cash stock, and overall operating expenses, which is estimated here as the sum of cost of goods sold, labor costs, and other operating expenses.
} 
(debt-to-asset ratio $=0.23$ ). This suggests that, on average, only about a quarter of assets were financed by external financing, mostly by bank loans. ${ }^{8}$ However, leverage ratios varied significantly across industries and by ownership structure (Figure 4). Firms in sectors linked to GVCs (electronics, machineries, textiles) were most leveraged. Entertainment, hospitality, travel, and other service sectors, while less profitable, had low leverage, reflecting higher reliance on own funds and lower relative dependence on bank and bond financing. SOEs, which have easier access to domestic bank financing, had the highest debt-to-equity ratios, particularly in mining and transportation. Compared to other countries in the region, micro and small firms relied mostly on internal funding, and were much less leveraged than similar-sized firms in other countries. While medium-sized firms were comparable to regional peers, large firms were much more leveraged, but relied less on foreign funding. ${ }^{9}$

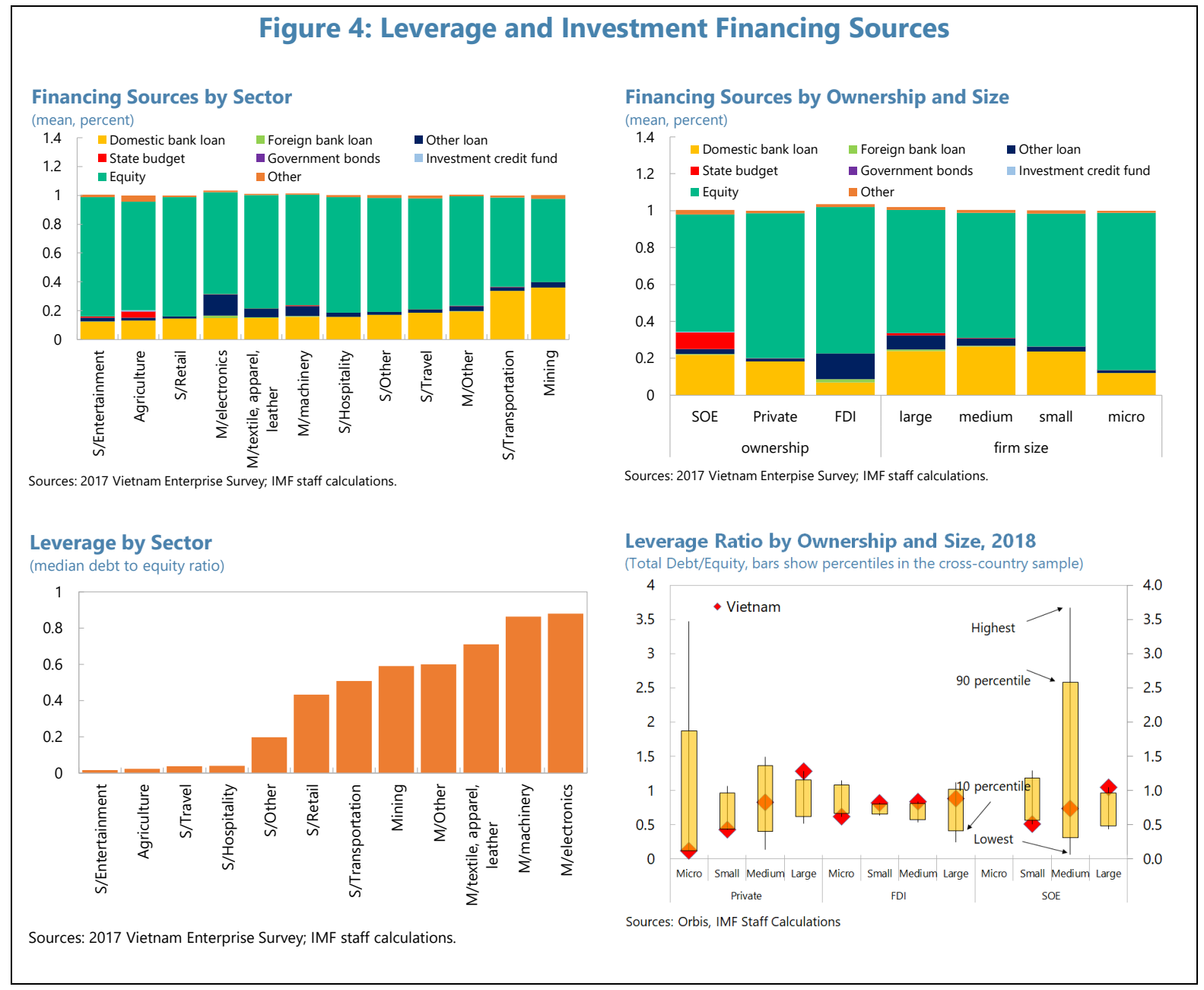

\footnotetext{
${ }^{8}$ A leverage ratio below 1 is typically considered "safe".

${ }^{9}$ See also Hayashi, Zhou, and Nga, "Vietnam: IMF Note on Impact of Covid-19 on the Banking System".
} 
Debt servicing capacity of Vietnamese firms was relatively weak, implying a high risk of default. The median interest coverage ratio (ICR) across Vietnamese firms, calculated as EBIT to interest payment ratio, was 1.3 in 2017, reflecting low profitability (Figure 5). ${ }^{10}$ The median ICR in the entertainment, hotel, and travel sectors was even lower than 1, suggesting that more than half the companies in these affected sectors faced problems meeting their interest payment obligations. SOE and FDI firms, and large firms (more than 200 employees) were in much better condition, with median ICR ratios higher than 2. Vietnam's debt servicing capacity is much weaker than the peers across ownership types and firm sizes (Figure 5). This reflects their lower profitability and higher financing costs for smaller firms, and higher leverage in larger firms.

Potential bank exposure to debt-at-risk was sizeable even prior to the COVID-19 shock. About 28 percent of corporate debt (90 percent through domestic bank loans) had an ICR below 1, that is at risk of default. Another 30 percent of corporate debt was in a relatively weak condition (ICR between 1 and 2). Industries with highest share of debt at risk $(I C R<1)$ were entertainment $(57$ percent), transportation (43 percent), and hospitality (51 percent). SOEs had a lower share of debt-at-risk (12 percent), in contrast to private firms (31 percent). Surprisingly, a sizeable share of debt in FDI firms also faced a high risk of default (37

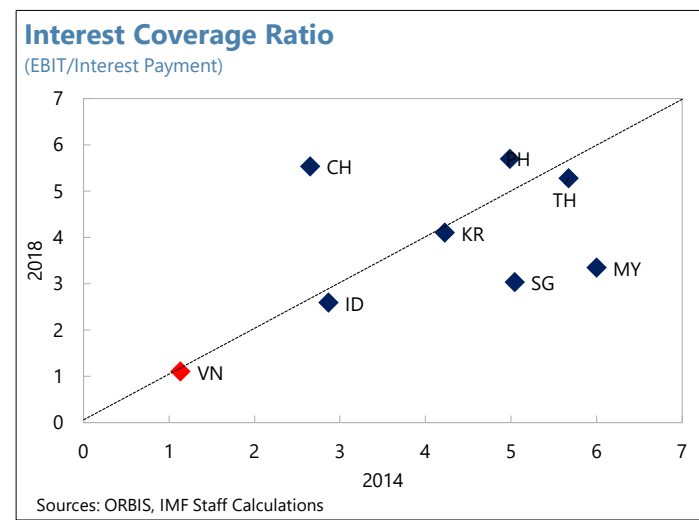
percent), most of them in the basic metal manufacturing industries.

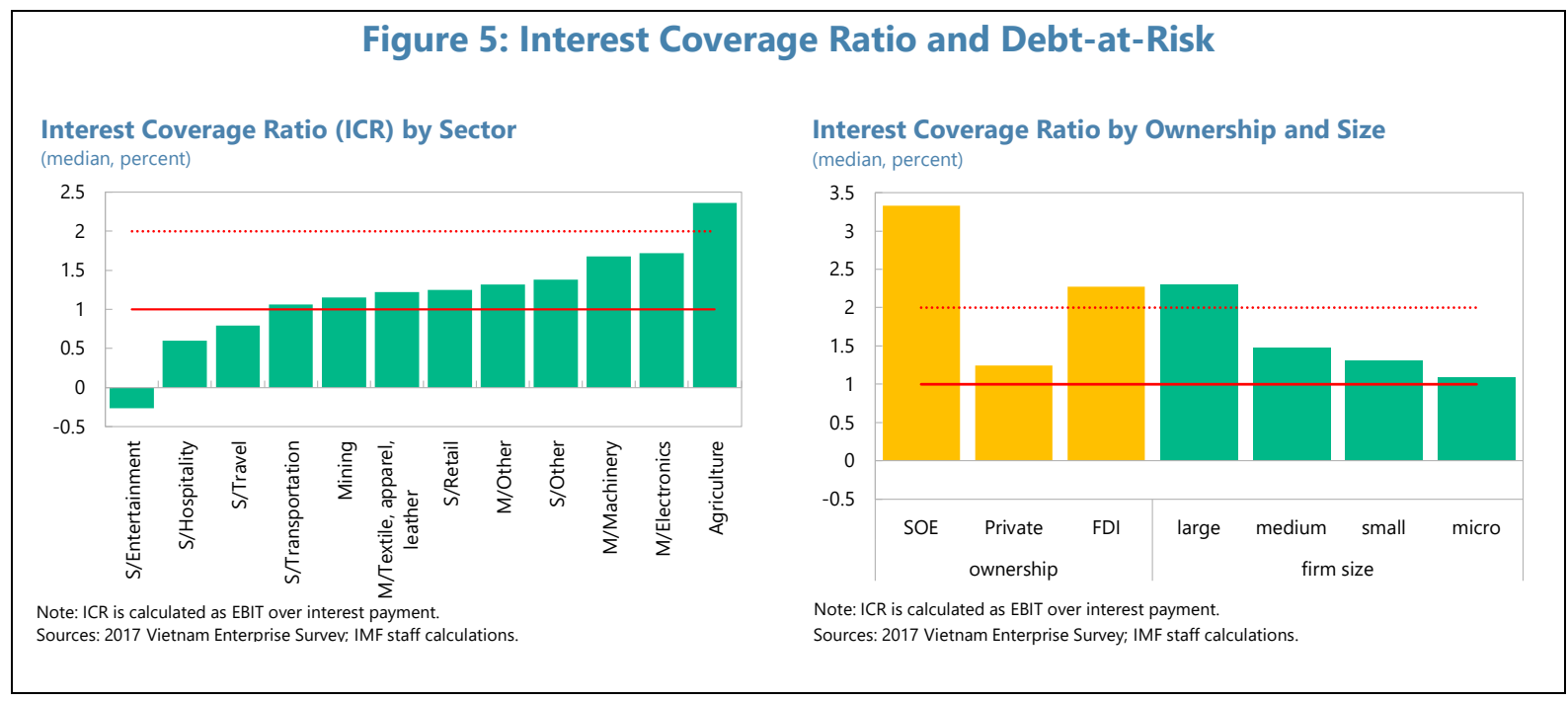

\footnotetext{
${ }^{10}$ Firms whose EBIT is less than interest payment due (i.e. ICRs of less than one) are sometimes referred as being in "technical default". In such situations, many of these firms can survive for some time by selling assets to meet their debt obligations, but if their ICRs remain below one for a sustained period, they eventually will run out of assets and actual default will ensue. A firm with an ICR between 1 and 2 is generally regarded as being at heightened risk.
} 


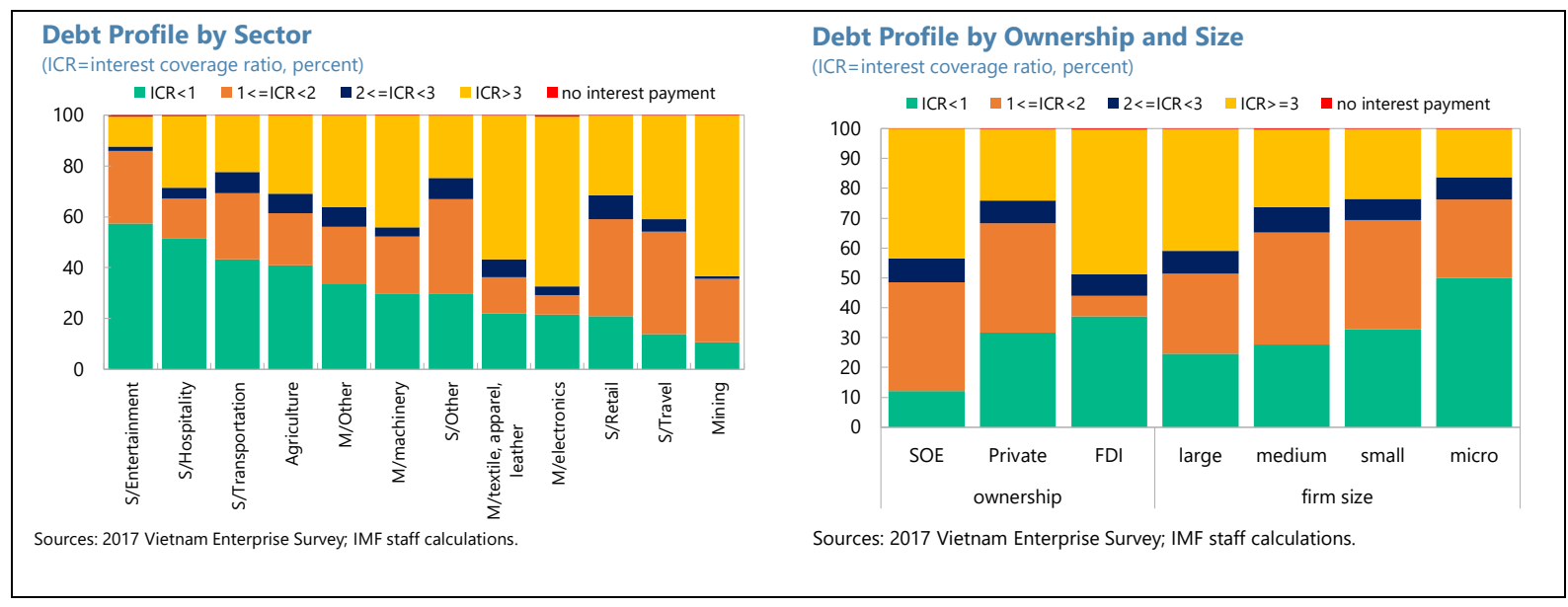

\section{IMPACT OF COVID-19: RISK OF DEFAULT, LABOR MARKET IMPLICATIONS, AND RISK PROPAGATION}

The COVID-19 shock will significantly weaken corporate profitability. Real GDP growth slowed significantly in the first half of 2020 amid heightened global uncertainties. We take firms' balance sheet conditions in the 2017 survey as the pre-COVID-19 baseline and calibrate shocks to firms' profitability based on assumptions about sectoral shocks to turnover that are consistent with country-level growth forecast in the October 2020 World Economic Outlook. This approach allows us to analyze the impact of the macro outturns on the liquidity and solvency position of firms. To calculate cash

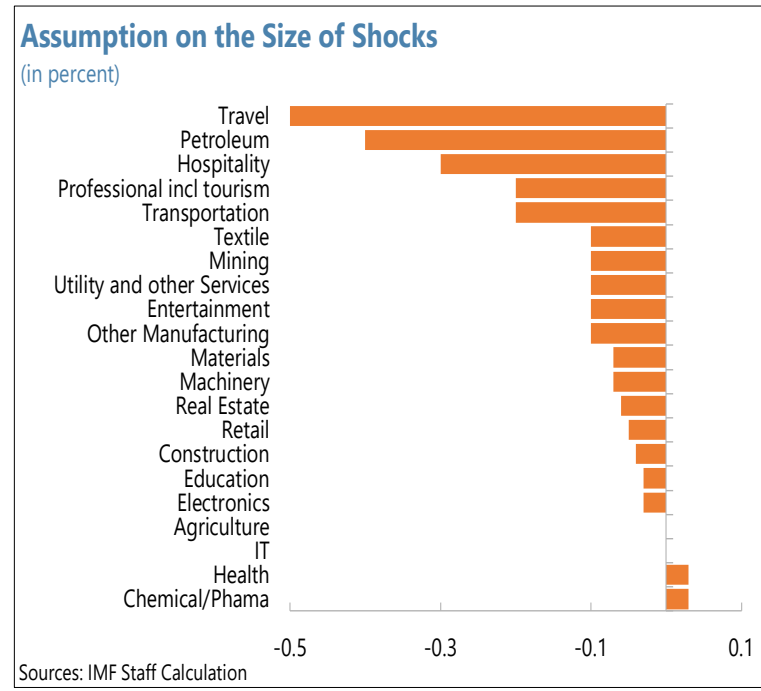
flows, the analysis assumes that firms can adjust their material costs in proportion to the reduction in sales, but continue to pay other obligations, such as wages, fixed costs, interest expenses, and debt repayments.

The COVID-19 crisis could substantially impair corporate cash flows. The impact on gross profits is expected to vary significantly across industries based on the sensitivity to the economic shutdown and decline in external demand by sector. Hospitality, personal transportation, travel and petroleum industries are most affected, with a decline in gross profits of over 40 percent. Manufacturing, retail, and business transportation face weaker demand and supply chain disruptions, and the impact on profitability is somewhat milder (10 percent decline in gross profits).

Falling profitability could create severe liquidity pressures. Assuming limited flexibility to reduce operational expenses in the short run, cash shortfalls would endanger firms' ability to cover shortterm liabilities. The simulated impact of the COVID-19 shock, however, varies across different types 
of firms. Our simulation suggests that around half of the small and micro firms would face negative cash flows, mostly in the hardest-hit sectors. It should be noted, however, that the number of firms facing liquidity constraints could be overstated if firms lay off workers, cut wages and other operational costs, and reduce their scale of operations, as was the case in Vietnam (Annex 5).

Firms' ability to service debt (solvency) would deteriorate, markedly raising debt-at-risk of default. On average, about 45 percent of the debt would be in distress, compared to 28 percent before the COVID-19 shock. Sectors that are hardest hit by the COVID-19 shock-hospitality, travel, and entertainment-also had the weakest financial health prior to the shock. Our simulation suggests that their debt-at-risk would increase from 50 to 80 percent, indicating a sharp increase in new defaults (see Text chart below, Table 1). The crisis could also put many SOEs, particularly airlines, in debt distress. Other industries with a high presence of SOEs (e.g. construction, agriculture, and utility) are less affected. Further, the stress test suggests that the corporate sector remains vulnerable to further demand shocks.

Risks could propagate more broadly given upstream and downstream linkages across industries. We calculate individual industries' upstream and downstream risk exposure using the 2015 input-output table for Vietnam from the OECD (Figure 6). ${ }^{11}$ Our analysis suggests that many service industries face a high indirect exposure from affected sectors. For example, while retail and hospitality are important suppliers to tourism and entertainment, the latter also provide services to the former. Manufacturing industries also face significant risk exposure as domestic suppliers of materials and parts are exposed to final producers (e.g. electronics/electrical equipment). The latter, in turn, are vulnerable to the external demand shock and global supply chain disruptions. Risk spillovers are also substantial between manufacturing and service sectors. For example, mining service providers are exposed to risks from mining/extraction industries and most manufacturing firms rely heavily on freight transportation. Corporate distress could spill over into the banks, exerting pressure on banks' profit margins and capital positions.

\footnotetext{
11 Upstream exposure is calculated as the average interest coverage ratio weighted by exposure to key suppliers. Downstream exposure is calculated as the average interest coverage ratio weighted by exposure to end users.
} 


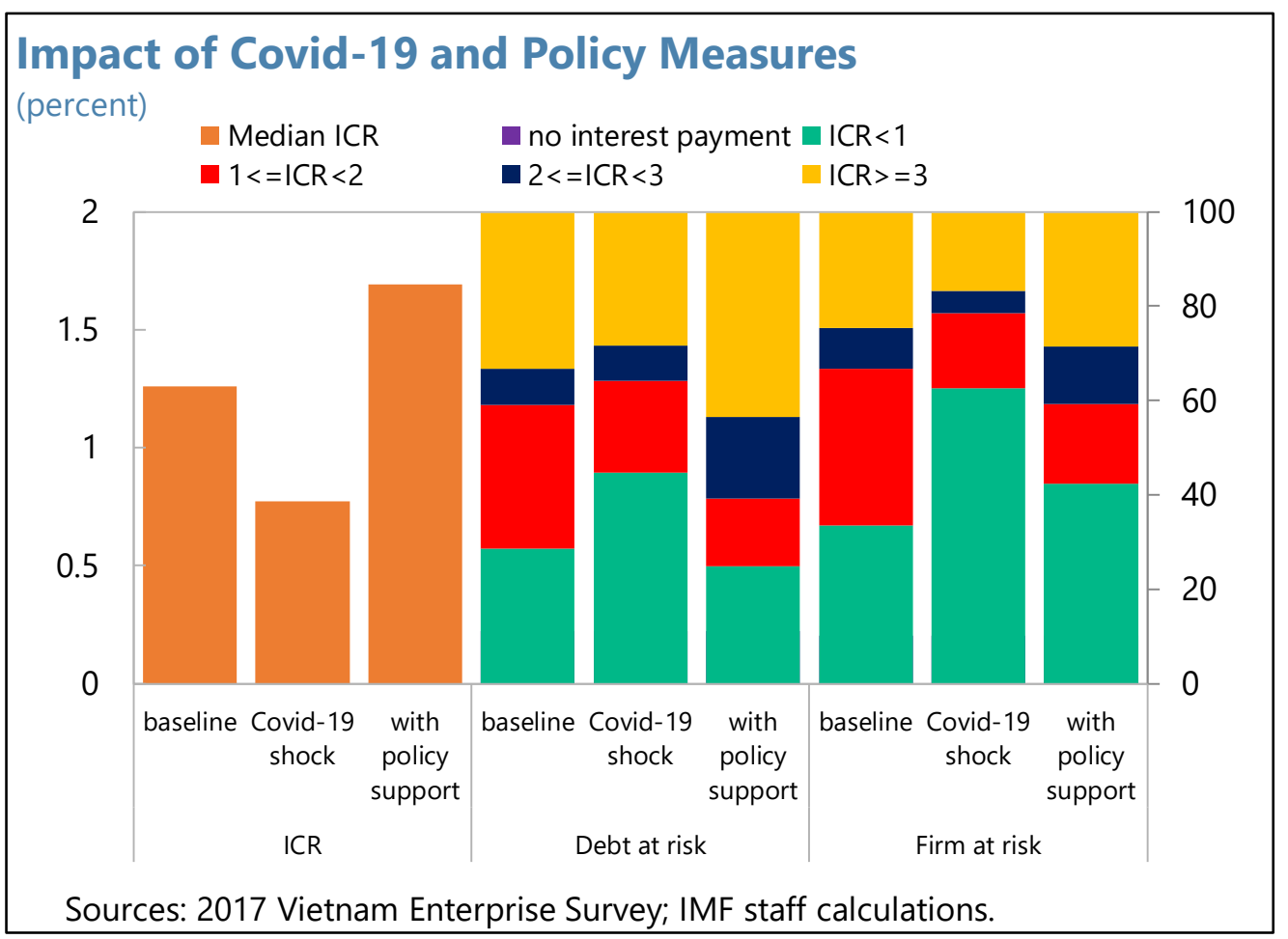

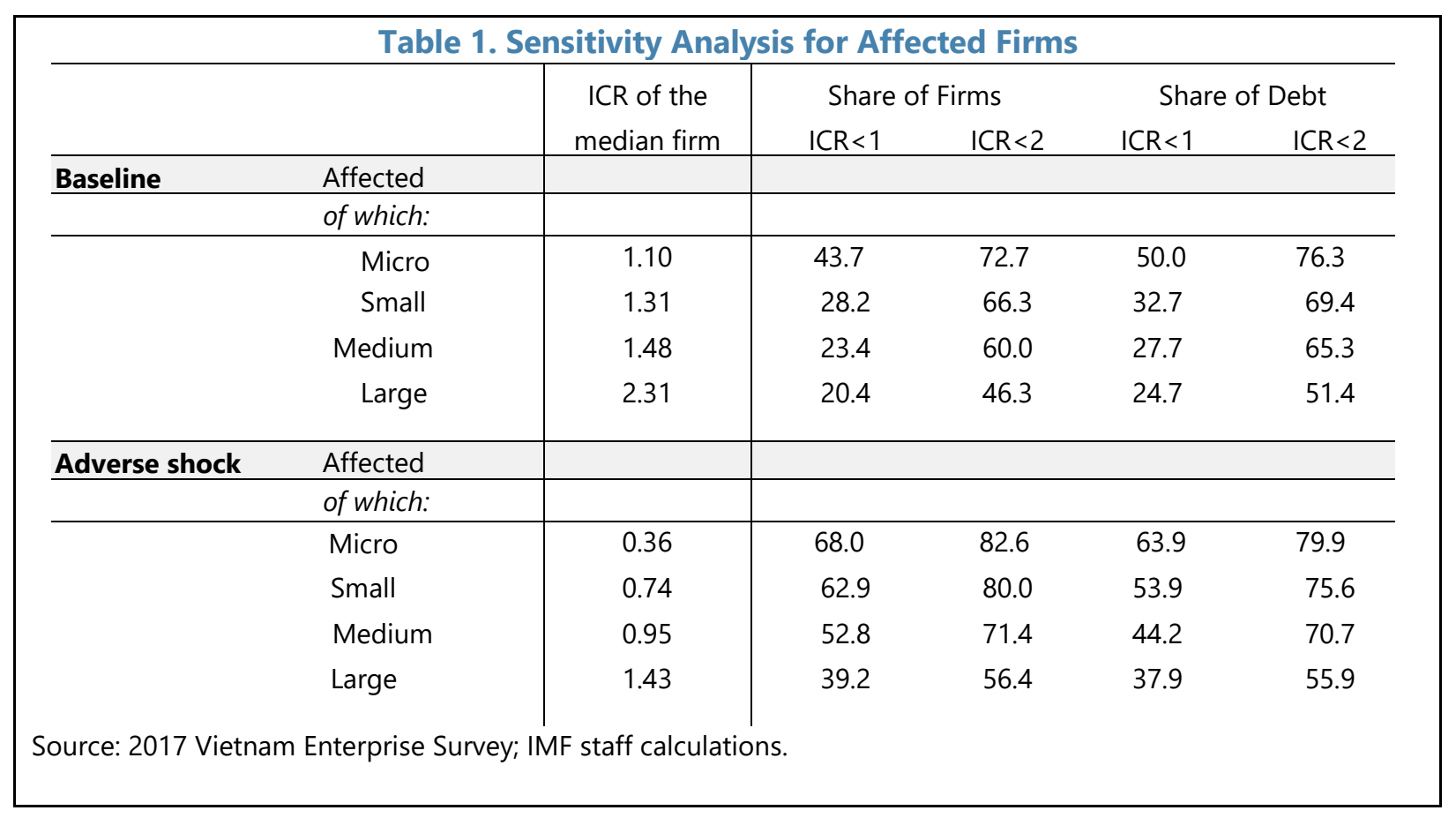


Figure 6: Upstream and Downstream Linkages Across Industries

\section{Downstream Exposure}

(weighed ICR by exposure to suppliers)

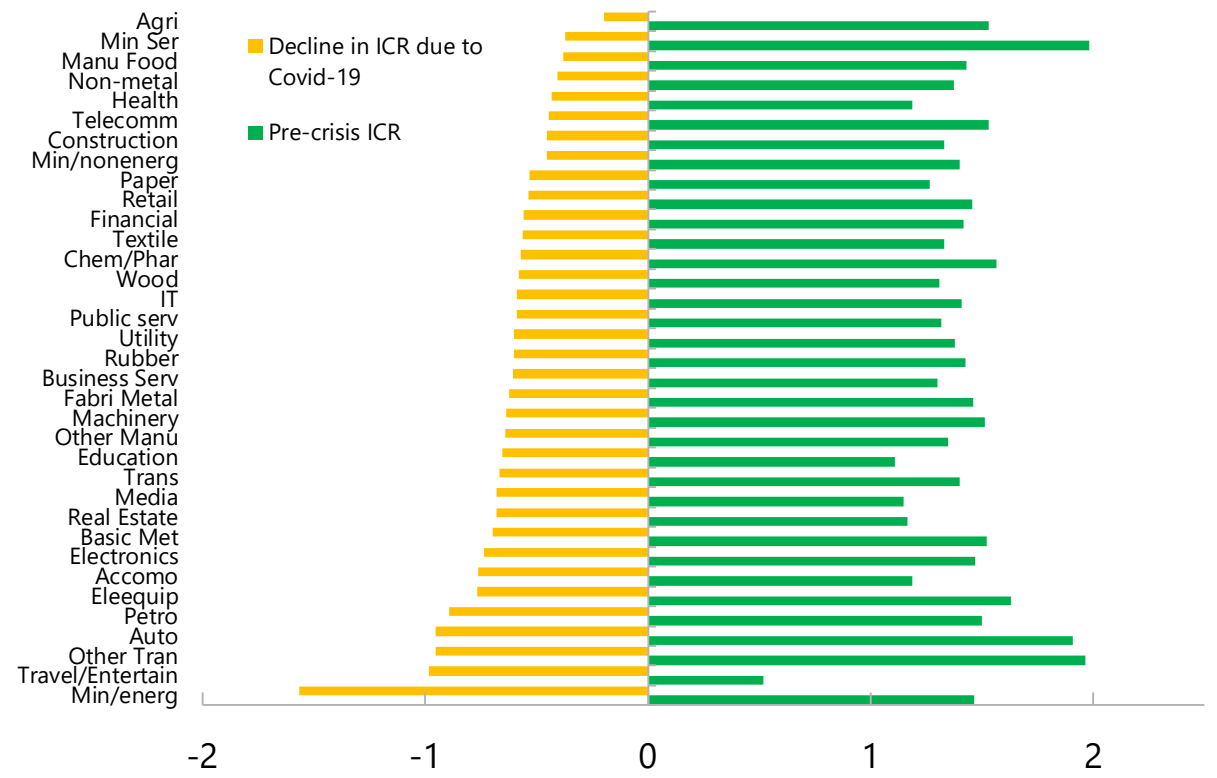

Sources: 2017 Vietnamnese Entreprise Survey, IMF Staff Calculations

\section{Upstream Exposure}

(Weighted ICR by exposure to suppliers)

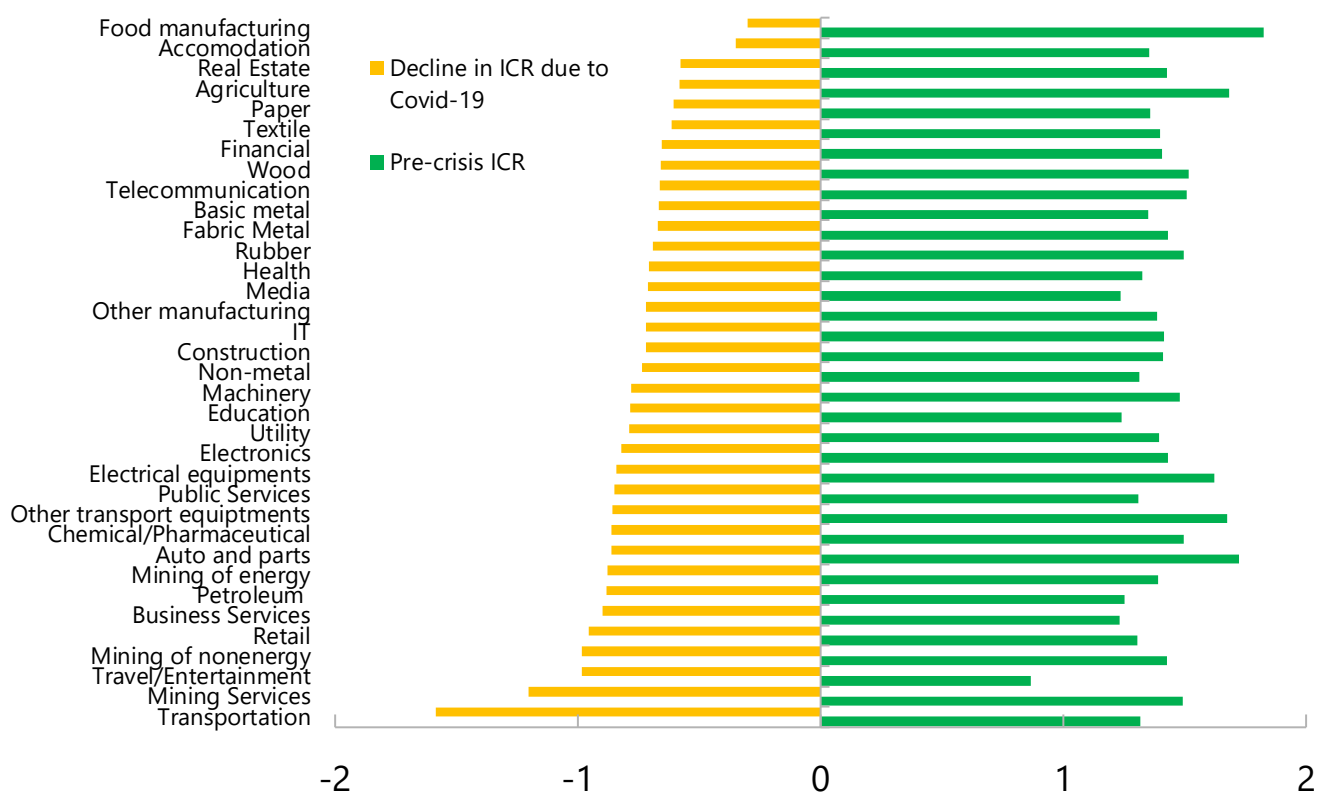

Sources: 2017 Vietnamnese Enterprise Survey, IMF Staff Calculations 
Corporate distress could have significant labor market implications. Firms with relatively weak initial balance sheet conditions accounted for a sizeable share of employment, with nearly half the workers employed under informal working arrangements (e.g., temporary or part-time contracts). ${ }^{12}$ As a result, workers in the affected industries are likely to face a higher risk of wage cuts or layoffs on account of the crisis. Assuming that the decline in firm earnings is absorbed by cutting back employment, around 28 percent of current employees could be laid off. Petroleum and service industries would face the most significant layoffs or decline in working hours, followed by transportation, travel, hospitality and entertainment sectors.

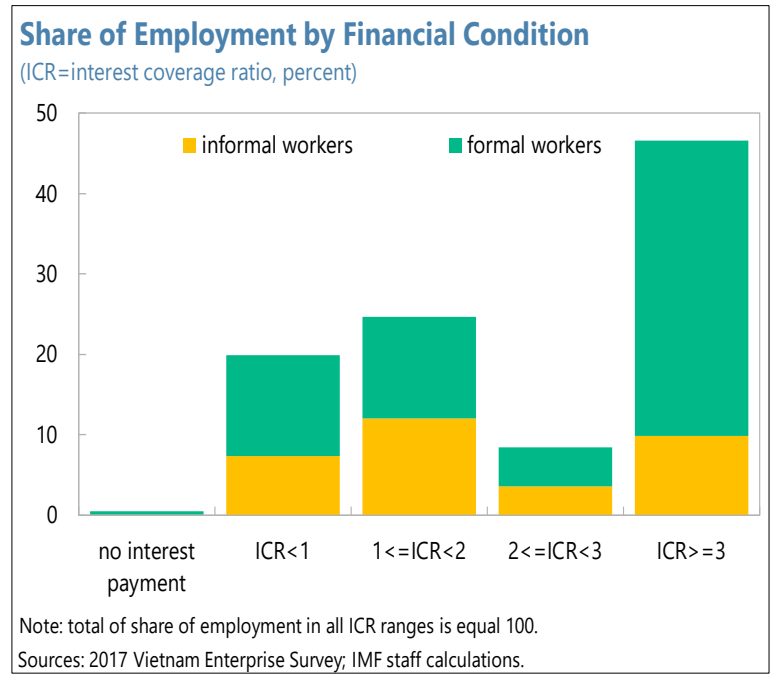

Workers in textiles and electronics, which are severely impacted by weaker global demand and supply chain disruptions, could also experience sizable downsizing or wage cuts.

\section{Mitigating Measures: Role of Policies}

A range of fiscal and financial measures were announced and implemented to alleviate liquidity pressures on firms in early 2020 (Annex 6). Fiscal measures include time-bound deferrals of VAT, CIT, land rental payment, and social security contribution, and cut in electricity prices that are expected to temporarily improve firms' liquidity positions. Financial measures, such as reducing or rescheduling interest payment on existing loans, would have a more direct impact on reducing debt service burdens. Other measures indirectly support firms' credit access by incentivizing banks to continue providing credit or new loans.

A simulation suggests that these measures combined could significantly improve firm liquidity and help cover nearly half of the shortfall in total cash flows. The simulation assumes that tax deferrals reduce firms' tax burden by half, electricity price subsidy reduce electricity-related payment by 10 percent, social security deferral relieves social security contribution for firms that would lay off more than 50 percent labor in the crisis. Similarly, financial policies are projected to reduce firms' interest payment obligation by 50 percent. The support received by firms is simulated at a granular level, taking into account conditions related to firm size, financial position, corporate type, economic sector, or turnover loss. The policy support is assumed to be time-bound and only affects financial health in 2020.

\footnotetext{
12 See Ganelli, Anh Thi Ngoc Nguyen, and Van Anh Nguyen, 2020, "Implications of the Covid-19 Shock for Vietnam's Labor Market and Policy Responses".
} 
Among the policy measures, debt moratoria and other financial measures such as new loans provided by banks contribute the most to lowering the liquidity gap. This reflects their large policy envelope and broad coverage.

We find that policy support measures could help mitigate the immediate risk of corporate default and layoffs. The above-mentioned measures would bring the share of debt-at-risk of default back to the pre-crisis level. Vulnerable debt $(I C R<2)$ would also decline significantly (see Figure 6, Text Chart above). Policies could also help mitigate job losses and potentially limit economic scarring. Focusing on the workers employed by and value added by firms that would have become illiquid but did not due to the policy support, our simulations suggests that potential employment layoffs would be significantly lowered from 28 to 18 percent.

It should be noted that our approach does not use information on the actual take-up rates of the various programs by different sectors and firms given limited information. As such, our findings could overestimate the ability of policies to mitigate liquidity and solvency risks. Notwithstanding this caveat, the announced measures could still provide important support to activity by boosting confidence and overall credit supply.

\section{ConClusions ANd Policy Implications}

Our analysis shows that the pandemic has increased the financial fragility of firms in Vietnam, although there is considerable heterogeneity in terms of balance sheet health. SMEs in Vietnam entered the crisis with relatively weak balance sheet conditions relative to other Asian countries and were hardest-hit by the COVID-19 shock. Their fragility is corroborated by evidence from a recent country-level survey which finds that they experienced significant declines in revenues and earnings on account of the pandemic. Larger enterprises were more profitable, but also highly leveraged on the eve of the crisis, even by regional standards Comparing across ownership types, we find that private firms were more vulnerable with weaker liquidity and solvency positions than FDI firms owing to both weaker profitability and higher leverage.

Emergency support measures put in place in the immediate aftermath of the shock have helped alleviate firms' liquidity constraints and labor market stress. However, firm's solvency conditions are weak, and liquidity buffers thin in comparison firms in other countries in the region. Liquidity shortfalls in SMEs could remain quite large, as could shortfalls in contact-intensive services sectors and in more complex value chains, such as garments and textiles. In the face of a protracted shock, firms could come under severe liquidity pressures or even solvency stress. ${ }^{13}$ As such policy support may have to continue for some time to support illiquid but viable firms until the recovery is on firmer

\footnotetext{
${ }^{13}$ It is important to treat these results with some caution as the analysis in this paper is a static exercise and does not address the impact on the banking system. Therefore, the analysis does not take into account second round effects, which may lead to higher unemployment, higher household bankruptcies and thus inflict additional losses on banks.
} 
ground. However, these measures will need to be gradually replaced by policies that are geared toward facilitating and supporting corporate restructuring and resolution.

The dispersion of corporate balance sheet conditions by size and ownership types, in part, reflects resource misallocation and pervasive economic duality. Larger private enterprises and foreign or state-owned enterprises have better access to external funding, and hence are more leveraged than the smaller private enterprises. Weaker profitability among the private SMEs reflects limited access to higher quality and cheaper inputs, heavier administrative burdens and poorer access to infrastructure (OECD, 2019).

A robust and sustained recovery and improved resilience of corporate balance sheets thus hinges on improving firm productivity by facilitating resource reallocation and improving labor skills. SMEs would benefit from better access to finance, technology, and market access. SMEs in Vietnam rely mostly on retained earnings as formal lending remains largely based on fixed-asset collateral and personal guarantees, which limits their potential to invest and grow. Further, they face onerous postregistration bureaucracy, which reduces incentives to formalize, invest, and reap economies of scale. Finally, improving the quality of training and higher education would help encourage entrepreneurship, innovation and productivity growth. 


\section{Annex 1. Summary Statistics of Key Variables Across Asian Countries}

\begin{tabular}{|c|c|c|c|c|c|c|c|c|c|c|c|c|c|c|c|c|}
\hline & \multicolumn{2}{|c|}{ Vietnam } & \multicolumn{2}{|c|}{ Indonesia } & \multicolumn{2}{|c|}{ Malaysia } & \multicolumn{2}{|c|}{ Philippines } & \multicolumn{2}{|c|}{ Singapore } & \multicolumn{2}{|c|}{ Thailand } & \multicolumn{2}{|c|}{ China } & \multicolumn{2}{|c|}{ Korea } \\
\hline & mean & median & mean & median & mean & median & mean & median & mean & median & mean & median & mean & median & mean & median \\
\hline Total assets & 22.02 & 1.58 & 6010 & 1460 & 5500 & 1010 & 5500 & 1010 & 2100 & 61.22 & 50.63 & 1.30 & 12300 & 906 & 971 & 15.94 \\
\hline Fixed assets & 9.32 & 0.00 & 3590 & 704 & 3560 & 428 & 3560 & 428 & 1280 & 4.90 & 29.32 & 0.23 & 7700 & 590 & 554 & 4.28 \\
\hline Equity & 9.64 & 0.84 & 2840 & 749 & 2790 & 583 & 2790 & 583 & 1060 & 25.15 & 24.65 & 0.89 & 4890 & 310 & 498 & 6.45 \\
\hline CVI & 0.10 & 0.10 & 0.03 & 0.03 & 0.07 & 0.07 & 0.07 & 0.07 & 0.01 & 0.01 & 0.06 & 0.06 & 0.02 & 0.02 & 0.13 & 0.13 \\
\hline ICR & 85.25 & 1.12 & 92.27 & 2.59 & 994.41 & 3.35 & 994.41 & 5.81 & 78.61 & 3.04 & 324.93 & 5.26 & 22.19 & 5.80 & 35.91 & 4.10 \\
\hline $\begin{array}{l}\text { EBIT / Assets } \\
\text { Gross profits / }\end{array}$ & -0.14 & 0.00 & 0.06 & 0.05 & 0.03 & 0.04 & 0.03 & 0.06 & 0.03 & 0.03 & 0.07 & 0.06 & 0.02 & 0.02 & 0.09 & 0.06 \\
\hline Assets & 0.28 & 0.04 & 0.22 & 0.18 & 0.21 & 0.16 & 0.21 & 0.16 & 1.80 & 0.123 & 0.38 & 0.24 & 0.46 & 0.33 & 0.45 & 0.25 \\
\hline Leverage ratio & 0.32 & 0.19 & 0.45 & 0.45 & 0.39 & 0.37 & 0.39 & 0.45 & 0.41 & 0.40 & 0.26 & 0.12 & 0.55 & 0.56 & 0.51 & 0.54 \\
\hline $\begin{array}{l}\text { Current ratio } \\
\text { Days cash on }\end{array}$ & 8.17 & 1.98 & 2.42 & 1.49 & 3.53 & 1.97 & 3.53 & 1.97 & 5.78 & 1.86 & 14.52 & 4.63 & 2.42 & 1.72 & 5.47 & 2.18 \\
\hline $\begin{array}{l}\text { hands } \\
\text { Cash flow }\end{array}$ & 65.08 & 10.72 & 72.49 & 30.79 & 105.30 & 54.69 & 144.30 & 54.69 & 143.79 & 76.09 & 303.71 & 110.14 & 73.15 & 45.51 & 15.67 & 5.19 \\
\hline ratio & & 0.00 & & 1.01 & & 0.61 & & 0.61 & & 0.29 & & 1.43 & & 1.28 & & 0.62 \\
\hline Observations & \multicolumn{2}{|c|}{507583} & \multicolumn{2}{|c|}{501} & \multicolumn{2}{|c|}{952} & \multicolumn{2}{|c|}{181} & \multicolumn{2}{|c|}{7346} & \multicolumn{2}{|c|}{232430} & \multicolumn{2}{|l|}{441} & \multicolumn{2}{|c|}{163965} \\
\hline Observations & \multirow{2}{*}{\multicolumn{2}{|c|}{996}} & \multirow{2}{*}{\multicolumn{2}{|c|}{1320}} & \multirow{2}{*}{\multicolumn{2}{|c|}{1115}} & \multirow{2}{*}{\multicolumn{2}{|c|}{1335}} & \multirow{2}{*}{\multicolumn{2}{|c|}{--}} & \multirow{2}{*}{\multicolumn{2}{|c|}{1000}} & \multirow{2}{*}{\multicolumn{2}{|c|}{2700}} & \multirow{2}{*}{\multicolumn{2}{|c|}{598}} \\
\hline WBES & & & & & & & & & & & & & & & & \\
\hline
\end{tabular}




\section{Annex 2. Overview of Vietnamese Enterprise Survey: Distribution by Firm Characteristics}

The survey covers 517,806 firms. Over 95 percent of the sampled firms are domestic and privately owned; only 4 percent of firms have foreign financing. SOEs account for less than 1 percent of the total sample. In terms of size, the sample is dominated by small (less than 50 employees) and micro firms (less than 10 employees). Large firms with more than 200 employees, and medium firms with more than 50 employees account for 2 and 5 percent of the total sample, respectively.

Most firms are in the service industries ( 80 percent), led by retail (40 percent) and construction (13 percent), hospitality, transportation and travel account for 3.5 percent, 6 percent, and 1 percent respectively. Manufacturing and mining industries account for 15 percent of the total sample; of which textile, machinery and electronics each only accounts for 2 percent, 1 percent and less than 1 percent respectively. A majority of the manufacturing firms are in the food and material industries. Most private firms are either small (20 percent) or micro (75 percent). Most

SOE firms are either medium (33) or large (40 percent). The size distribution across FDI firms is more uniform (25 percent in each size category). Firms with foreign financing have very little presence in the service sectors $(1.5$ percent on average). Firms in IT, real estate, professional services have more foreign presence than average. Most FDI firms are in the manufacturing industries, led by electronics, electrical and transportation equipment, and textiles. In terms of employment, only 3 percent of employees are hired by agricultural industries; another 50 percent are in manufacturing; and the rest in service industries. A majority of employees are hired by private firms (60 percent); FDI firms accounts for another 30 percent. It is also likely that some of the informal workers are not reported in the survey, underestimating the actual number of workers in smaller firms.

In terms of total sales and assets, service sectors account for more than half the sample. Retail, electronics, construction, utility and transportation represent the largest share. Large, private firms account for 50 percent of sales; SOEs account for only 18 percent of total sales, but account for 30 percent of total assets in the corporate sector. 
Annex 3: Summary Statistics of Vietnamese Enterprise Survey

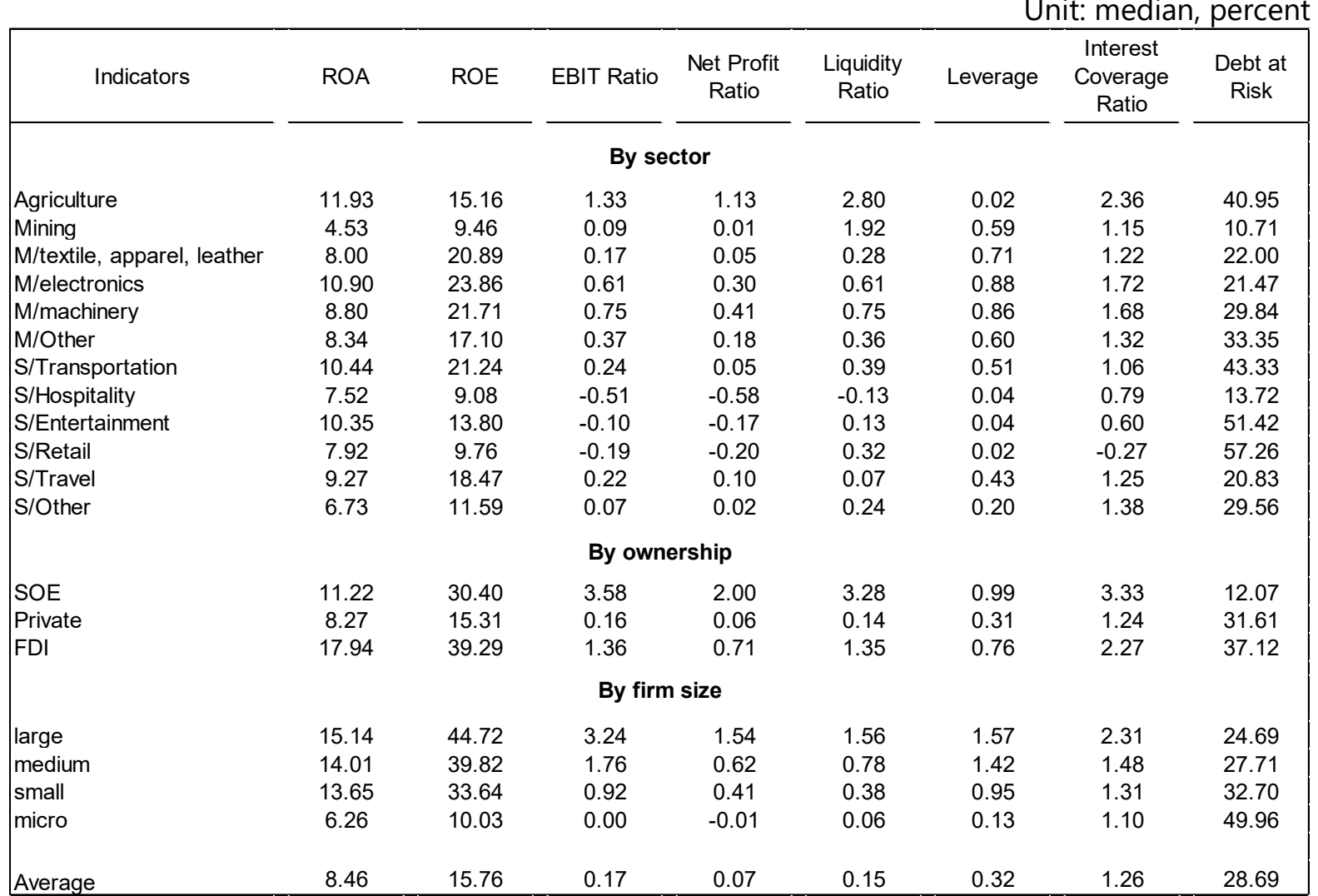

Note: (a) ROA is gross profit ratio to total assets ratio; ROE is gross profit to equity ratio; EBIT Ratio is earning before interest and tax to total assets ratio; Net Profit Ratio is the net profit to total assets ratio; Liquidity Ratio is the net operating cash flow (EBIT + amortization - tax) to current liability ratio; Leverage is debt to equity ratio; Interest Coverage Ratio (ICR) is EBIT to interest payment ratio; and Debt at Risk ratio is the share of debt at risk of default: ICR <1. (b) M and $S$ denote manufacturing and services, respectively.

Source: 2017 Vietnam Enterprise Survey; IMF staff calculations. 


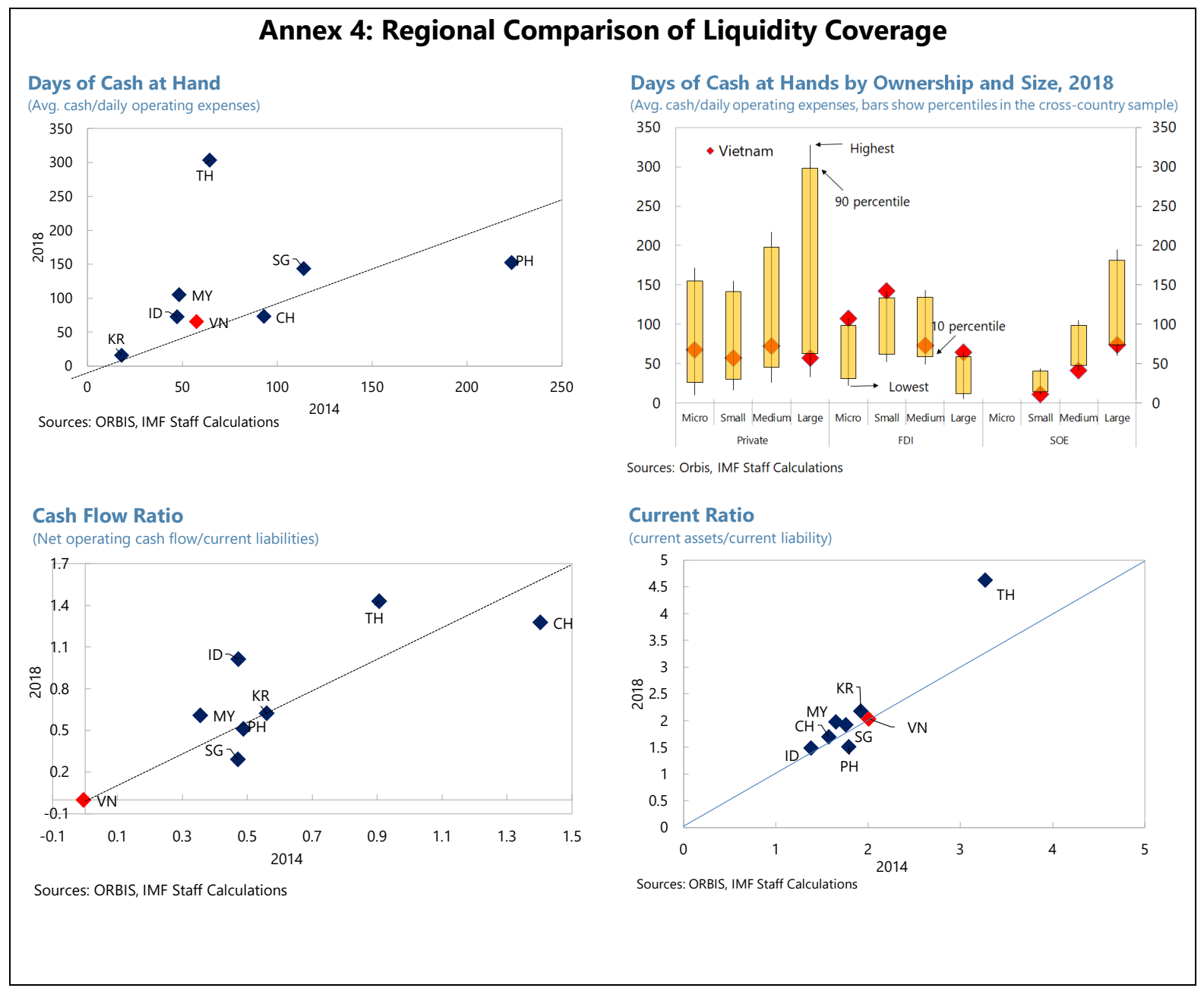




\section{Annex 5: Recent Firm-level Survey on the Impact of COVID-19}

A survey conducted in early April 2020 by the National Economics University of Vietnam (NEU) in April covering around 700 firms provides insights on the COVID-19 impact on firms. Firms reported difficulties stemming from a sharp decline in revenue to cover business costs ( 60.3 percent) and under-scale production (53.6 percent); and to a lesser extent from production and supply chain disruptions and depressed demand. Firms have been responding to the shock by cutting costs (i.e., reducing operating expenses, laying off employment, cutting wages or asking employees to

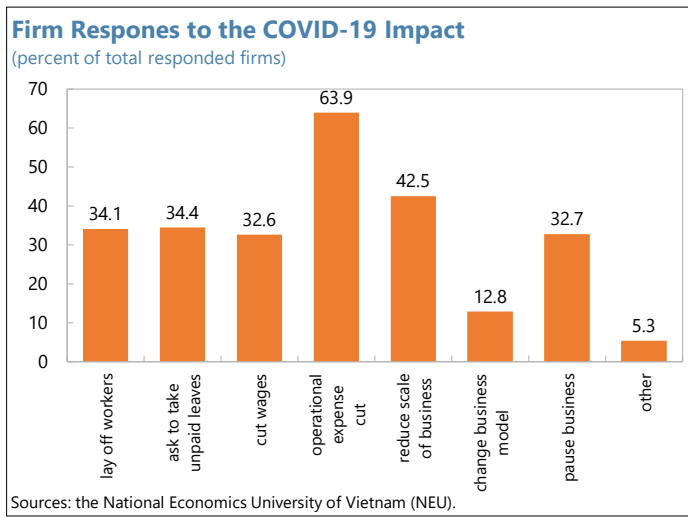
take unpaid leave) and/or by changing business models (reducing the scale of production, pausing businesses or shifting their business model).

If the pandemic outbreak and associated domestic containment measures were to persist for an extended period, a large number of firms would be adversely impacted. The longer the outbreak continues, the higher proportions of firms that would either suspend their operations or go bankrupt. In an extreme scenario, if the outbreak were to last until end-year, 38 percent of firms reported that they would go bankrupt and another 36 percent would have to suspend its business. FDI firms are likely to more immune to the shock as their financial resilience also depend on parent

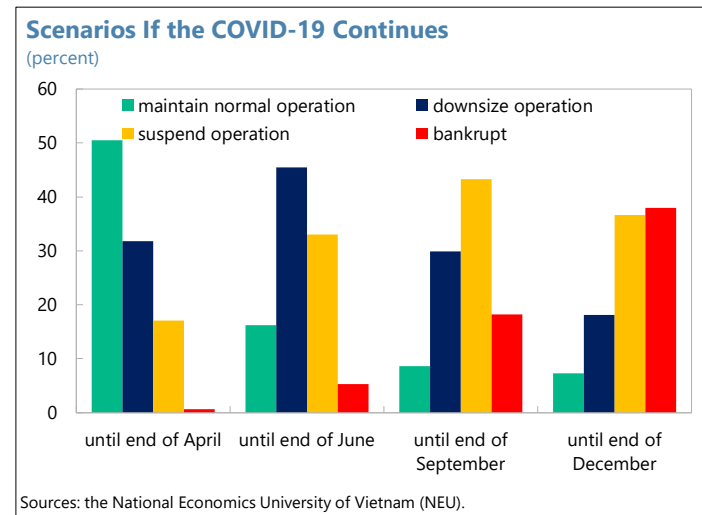
company health, while SOEs are the most vulnerable to bankruptcy if the outbreak is prolonged. 


\section{Annex 6: Key Policy Measures to Support Businesses in Response to COVID-19}

\section{Fiscal:}

$\checkmark$ Deferral of consumption tax (VAT) and corporate income tax (CIT) as well as land rental payment for 5 months for affected firms.

$\checkmark$ Deferral of social security contribution (up to 12 months) for both affected firms and workers if the number of employees in a firm falls below 50 percent.

$\checkmark$ Up-to-10 percent cut (for 3 months) in electricity prices for industrial and service enterprises and businesses.

$\checkmark$ CIT incentive scheme introduced for micro and small enterprises from July 1 , to alleviate business difficulties amid the COVID-19 pandemic.

$\checkmark$ Cuts in various fees and charges (water resources, construction project evaluations, road tolls, seaport charges, aviation service charges, road maintenance fees).

$\checkmark$ Extension of exemptions and reductions of environmental protection tax on gasolines.

\section{Monetary and Financial:}

$\checkmark$ Three times of policy rates cut by 50-100 bps, short-term deposit rates cap by 25-30 bps, and the short-term lending rates cap for priority sectors by 50 bps.

$\checkmark$ Credit package. With the coordination of SBV, credit institutions (Cls) rolled out a VND 300 trillion credit support package in March on a voluntary basis. The credit package aims to provide new loans to borrowers at lower interest rates (by 0.5-2.5 percent) compared to the pre-COVID 19 interest level.

$\checkmark$ Exempt and reduced interest rate for existing loans. Interest payments of 464 thousand clients were either reduced or exempted between March and Mid-Aug.

$\checkmark$ Rescheduled/restructured loans. The SBV allowed Cls to reschedule/restructure loans for eligible clients, while keeping the loans in the original grading group. Between March to mid-August, Cls have restructured/rescheduled loans for 265,000 clients with outstanding loans of VND 310 trillion (3.6 percent of total system outstanding loans).

$\checkmark$ Cls reduced transaction fees for payment transactions in small amounts (estimated the total reduction of VND 1 trillion).

$\checkmark$ Vietnam Social Policy Bank (VPSB)loans with SBV refinancing (VND 16 trillion) to provide zero-interest-rate loans for affected firms that maintain employees on payroll.

Note: A full version of policy responses by the Vietnamese government can be found at https://www.imf.org/en/Topics/imf-and-COVID19/Policy-Responses-to-COVID-19 


\section{REFERENCES}

Albonico, M., Mladenov, Z., Sharma, R., 2020, "How the COVID-19 Crisis Is Affecting UK Small and Medium-Size Enterprises". McKinsey Article.

Asia and Pacific Regional Economic Outlook, 2019, "Caught in Prolonged Uncertainty", International Monetary Fund.

Baldwin, R., Mauro, B., 2020, "Mitigating the COVID Economic Crisis: Act Fast and Do Whatever it Takes", VoxEU.

Boot, A., Carletti, E., Kots, H., Krahnen, J., Pelizzon, L., Subrahmanyam, M., 2020, "Coronavirus and Financial Stability 2.0: Act Jointly Now, But Also Think About Tomorrow".

Colacelli, M., Hong, G., 2019, "Productivity Drag from Small and Medium-Sized Enterprises in Japan", IMF Working Paper No. 19/137.

Demmou, L., Franco, G., Calligaris, S., Dlugosch, D., 2020, "Corporate Sector Vulnerabilities During the COVID-19 Outbreak: Assessment and Policy Responses", OECD papers.

Didier, T., Huneeus, F., Larrain, M., Schmukler, S., 2020, "Financing Firms in Hibernation During the COVID-19 Pandemic", World Bank Research and Policy Briefs, No. 147598.

Dudine, P., Hayashi, T., 2020, "Fiscal and Financial Risks of State-Owned Enterprises in Vietnam", IMF Note.

Fiscal Monitor, 2020, "Fiscal Policies to Address the Pandemic", October 2020.

Ganelli, G., Nguyen, A., Nguyen, V., 2020, "Implications of the COVID-19 Shock for Vietnam's Labor Market and Policy Responses", IMF Note.

Hayashi, T., Zhou, Y., Ha, N., 2020, "Vietnam: IMF Note on Impact of COVID-19 on the Banking System", IMF Note.

Kim, M., Li, X., Yoo, J., 2020, "Nonfinancial Corporate Vulnerability in Emerging Asia" IMF Note.

Regional Economic Outlook: Asia and Pacific, 2020, "Navigating the Pandemic: A Multi-Speed Recovery in Asia", October 2020, International Monetary Fund.

Yoshino, N., Taghizadeh-Hesary, F., 2018, "Major Challenges Facing Small and Medium-Sized Enterprises in Asia and Solutions for Mitigating Them", ADBI Working Paper, 564. 